\title{
Familial coexistence of achalasia and non-achalasic oesophageal dysmotility: evidence for a common pathogenesis
}

\author{
C J O’Brien, H L Smart
}

\begin{abstract}
In five of seven siblings of healthy parents, dysphagia developed during adolescence or early adult life. A barium swallow was normal in one patient but showed appearances considered to be consistent with achalasia in all others. Oesophageal manometry was successfully performed in four of the five patients, including the patient with symptoms but normal radiological appearance. One patient had achalasia, two had oesophageal body motor dysfunction associated with a hypertensive, but normally relaxing lower oesophageal sphincter, and one had diffuse oesophageal spasm alone. The occurrence of three different oesophageal dysmotility disorders within members of a single sibship suggests that these conditions are intimately related and probably genetically determined as an autosomal recessive trait.
\end{abstract}

(Gut 1992; 33: 1421-1423)

Achalasia is a very uncommon condition with an incidence in the United Kingdom of less than $1 / 100000$ per annum. ${ }^{1}$ Its cause is unknown and although familial clustering can provide clues this is extremely rare and when found usually involves two related cases only. ${ }^{2-12}$ We have recently seen five siblings with dysphagia from a single family in whom investigation showed a variety of oesophageal motor disorders including achalasia. This is the largest number of related cases of abnormal oesophageal motility of mixed types ever documented.

\section{Case reports}

SIBLING 1

A 27 year old South Yorkshire miner was referred from his local hospital for pneumatic dilatation. He had suffered progressive dysphagia since the age of 16 years and a barium study was reported as showing achalasia (Table).

Gastroenterology Unit, Royal Hallamshire Hospital, Sheffield C J O'Brien H L Smart

Correspondence to: Dr C J O'Brien, Daisy Hill
Hospital, Newry, Co Down BT35 8DR.

Accepted for publication

11 May 1992
A younger brother had previously undergone investigation and surgery for achalasia. The subject was unable to tolerate oesophageal manometry. Endoscopy showed food retention within a dilatated oesophagus, associated with a tight, non-obstructed gastro-oesophageal junction. Pneumatic dilatation was performed. At subsequent clinical review the patient reported a considerable improvement in his ability to swallow and had gained weight. He had no disturbance of bowel habit or evidence of intestinal obstruction distal to the cardia on plain abdominal $x$ ray. Further enquiry into the patient's family history showed that in addition to his younger brother who had previously undergone operation (sibling 2), three other members of his family (two brothers and one sister: siblings 3, 4, and 5) also suffered from long standing dysphagia for solids, although this had not been investigated.

\section{SIBLING 2}

Review of this patient's notes showed that five years previously, when aged 16 , he had been referred to our own unit with a one year history of increasing dysphagia and a recent right basal pneumonia. Barium radiology showed achalasia, confirmed by oesophageal manometry (Table). He underwent a Heller's myotomy with fundoplication and is now asymptomatic.

\section{SIBLING 3}

This 29 year old coal miner had had mild, intermittent painless dysphagia for solids since his schooldays but had not sought medical attention. A barium swallow with marshmallow showed no abnormality but oesophageal manometry was consistent with the diagnosis of diffuse oesophageal spasm $^{13}$ (Table). He declined any therapy for his symptoms.

\section{SIBLING 4}

This 22 year old man, also a coal miner, had noted intermittent dysphagia for solids, accompanied by occasional regurgitation of food, for 2 years. Barium radiology was compatible with achalasia (Table). Oesophageal manometry showed a hypertensive but normally relaxing lower oesophageal sphincter with disruption of body motor function compatible with an indeterminate oesophageal motility disorder ${ }^{13}$ (Table). Because of his symptoms he was treated with sublingual nifedipine before meals which produced significant improvement.

\section{SIBLING 5}

This 33 year old housewife had developed inter- 
Radiological and manometric findings in a family with achalasia and non-achalasic oesophageal dysmotility

\begin{tabular}{|c|c|c|c|c|}
\hline & \multirow[b]{2}{*}{ Barium swallow } & \multicolumn{3}{|c|}{ Oesophageal manometry } \\
\hline & & $\begin{array}{l}\left.\underset{\mathrm{LOSP}}{\mathrm{LOH}} \mathrm{O}_{2} \mathrm{O}\right)^{\star}\end{array}$ & $\begin{array}{l}\text { LOS relaxation } \\
\text { with swallowing }\end{array}$ & Body motility \\
\hline Sibling 1 & Dilated; food residue, distal & \multicolumn{3}{|c|}{ Unable to tolerate manometry } \\
\hline Sibling 2 & Dilated; food residue, distal & 30 & Absent & Absent \\
\hline Sibling 3 & $\begin{array}{l}\text { Normal including marshmallow } \\
\text { study }\end{array}$ & 25 & Normal & $\begin{array}{l}\text { Repetitive, simultaneous } \\
\text { waves }(>65 \%) \text {; some } \\
\text { normal peristalsis }\end{array}$ \\
\hline Sibling 4 & Dilated; distal obstruction & 52 & Normal & $\begin{array}{l}\text { Repetitive, simultaneous } \\
\text { waves; low amplitude; } \\
\text { no normal peristalsis }\end{array}$ \\
\hline Sibling 5 & $\begin{array}{l}\text { Normal; delayed marshmallow } \\
\text { transit }\end{array}$ & 45 & Normal & $\begin{array}{l}\text { Repetitive, simultaneous } \\
\text { waves; low amplitude; } \\
\text { no normal peristalsis }\end{array}$ \\
\hline Sibling 6 & Not performed & 24 & Normal & Normal peristalsis \\
\hline Sibling 7 & Not performed & 22 & Normal & Normal peristalsis \\
\hline Mother & Not performed & 27 & Normal & Normal peristalsis \\
\hline
\end{tabular}

LOS = lower oesophageal sphincter; $L O S P=$ lower oesophageal sphincter pressure.

$\star$ Normal range for our laboratory $10-35 \mathrm{cmH}_{2} \mathrm{O}$. mittent dysphagia for solids in childhood. There was no chest pain. Standard barium radiology was normal but there was a considerable delay in the transit of a half marshmallow from the cricopharyngeous to the stomach, indicative of a motor disorder (Table). Oesophageal manometry showed an indeterminate oesophageal motor disorder (Table).

She was initially treated with sublingual nifedipine to good effect but developed intolerance and had side effects of flushing and headaches. Subsequently, diltiazem $(60 \mathrm{mg}$ thrice daily) produced almost complete resolution of her symptoms.

SIBLINGS 6 AND 7

A brother aged 35 and sister 31 years had no oesophageal symptoms and oesophageal manometry was normal in both cases (Table).

\section{PARENTS}

Both parents are in their late 50s and do not have swallowing difficulties. They are not blood relatives and there is no known family history of oesophageal disease. The father was unwilling to attend hospital. Oesophageal manometry in the mother was normal (Table).

\section{LABORATORY TESTING}

Routine haematology and biochemistry were normal in the cases with dysphagia. In particular, there were no electrolyte abnormalities or evidence of malabsorption and random serum cortisol values were within the normal range. Oesophageal and duodenal biopsy specimens were negative for amyloid. Chromosomal analysis on affected siblings ( 1 and 4 ) showed a normal karyotype.

\section{Discussion}

Manometric examination of this unique kinship has documented the co-occurrence of classical achalasia, diffuse oesophageal spasm, and indeterminate oesophageal motor disorder. This strongly indicates that these conditions can share a common pathogenesis, although they seem to be separate entities. Oesophageal spasm progressing to achalasia is infrequently found. Vantrappen and Hellemans observed such an evolution in only 6 of 156 patients they studied. ${ }^{1+}$ In vigorous achalasia, with which diffuse oesophageal spasm can be confused, orderly relaxation of the lower oesophageal sphincter is invariably absent. ${ }^{15}$ It is improbable that three of the patients we describe could have varient achalasia since all had normally relaxing sphincters. Also against evolving disease is the observation that the sibling with classical achalasia had the shortest history while those with indeterminate dysmotility had either very longstanding dysphagia or had developed oesophageal dilatation.

Earlier reports describing the coincidence of achalasia and diffuse oesophageal spasm in a mother and son ${ }^{9}$ and brother and sister ${ }^{16}$ pair may be further examples of dysmotility disease linkage. Interpretation of these reports is tempered by the fact that oesophageal manometry was not performed in one of each pair before sphincter surgery, and in one further case the diagnosis of achalasia was made only at post mortem: In other situations, where familial achalasia has been reported on radiological findings alone, the cooccurrence of mixed dysmotility disease may have been overlooked.

The appearance of significant oesophageal dysfunction in five of seven siblings of healthy parents is we believe most probably the result of a genetic trait. Familial clustering with vertical transmission has previously been found but horizontal transmission, although still very rare, is four to five times more common. ${ }^{9}$ Multiple cases have also been a feature of consanguinous marriages. ${ }^{10121718}$ However, Mayberry and Atkinson ${ }^{19}$ in a systematic review of over 1000 first degree relatives of patients with achalasia, did not detect any with primary oesophageal dysfunction. These findings and those in our own family point, therefore, to the possibility that primary disorders of oesophageal function may occasionally reflect the expression of an autosomal recessive gene. In the future, DNA studies of achalasia/oesophageal dysmotility families may provide clues to the abnormalities at molecular level that could underlie the development of these related disorders.

We thank Mr R Avill who referred sibling 1, Dr M C Collins for expert radiological help, Dr C D Holdsworth for review of the manuscript, and Dr D Kumar of the Centre for Human Genetics, Sheffield for chromosomal analysis.

1 Mayberry JF, Atkinson M. Variations in the prevalence of achalasia in Great Britain and Ireland: an epidemiological study based on hospital admissions. $Q \mathcal{F}$ Med 1987; 62: 67-74.

2 Nagler RW, Schwartz RD, Stahl WM, Spiro HM. Achalasia in fraternal twins. Ann Intern Med 1963; 59: 906-10.

3 London FA, Raab DE, Fuller J, Olsen AM. Achalasia in three siblings: a rare occurrence. Mavo Clin Proc 1977; 52 97-100.

4 Bosher LP, Shaw A. Achalasia in siblings: clinical and genetic aspects. Am F Dis Child 1981; 135: 709-10.

5 Stoddard CJ, Johnson AG. Achalasia in siblings. Br $\mathcal{F}$ Surg 1982; 69: 84-5.

6 Stein DT, Knauer CM. Achalasia in monozygotic twins. Dig Dis Sci 1982; 27: 636-40.

7 Zimmerman FH, Rosensweig NS. Achalasia in a father and son. Am f Gastroenterol 1984; 79: 506-8.

8 Tryhus MR, Davis M, Griffith JK, Ablin DS, Gogel HK. Familial achalasia in two siblings: significance of possible hereditary role. F Pediatr Surg 1989; 24: 292-5.

9 Frieling T, Berges W, Borchard F, Lubke HJ, Enck P, 
Wienbeck M. Family occurrence of achalasia and diffuse spasm of the oesophagus. Gut 1988; 29: 1595-602.

10 Dayalan N, Chettur L, Ramakrishnan MS. Achalasia of the cardia in sibs. Arch Dis Child 1972; 47: 115-8.

11 Badrawy R, Abou-Bieh A. Congenital achalasia of the oesophagus in children. F Laryngol Otol 1975; 89: 697-706 2 Westley CR, Herbst JJ, Goldman S, Wiser WC. Infantile achalasia inherited as an autosomal recessive disorder. achalasia inherited as an

13 Vantrappen G, Hellemans J. Oesophageal spasm and other muscular dysfunction. In: Connell AM, ed. Clinics in gastroenterology: motility and its disturbances. London: WB Saunders, 1982: 453-77.

14 Vantrappen G, Hellemans J. Diffuse muscle spasm of the oesophagus and the hypertensive lower oesophageal sphincter. In: Atkinson M, ed. Clinics in gastroenterology: disorders of oesophageal motility. London: WB Saunders, 1976: 59-72.

15 Sanderson DR, Ellis FH, Schlegel JF, Olsen AM. Syndrome of vigorous achalasia: clinical and physiologic observations. Dis Chest 1967; 52: 508-17.

16 Kaye MD, Demeules JE. Achalasia and diffuse oesophageal spasm in siblings. Gut 1979; 20: 811-4.

17 Rozycki DL, Rubin RJ, Rapin I, Spiro AJ. Autosomal recessive deafness associated with short stature, vitiligo, muscle wasting and achalasia. Arch Otolaryngol 1971; 93:

18 Khalifa MM. Familial achalasia, microcephaly and mental retardation. Clin Pediatr 1988; 27: 509-12.

19 Mayberry JF, Atkinson M. A study of swallowing difficulties in first degree relatives of patients with achalasia. Thorax 1985; 40: 391-3. 